\title{
Effect of feed type and method of presentation on feeding behavior, intake, and growth of dairy calves fed a high level of milk
}

\author{
M. A. Overvest, ${ }^{*}$ R. Bergeron, $†$ D. B. Haley, $\ddagger$ and T. J. DeVries ${ }^{* 1}$ \\ ${ }^{*}$ Department of Animal and Biosciences, University of Guelph, Guelph, ON, N1G 2W1, Canada \\ †Department of Animal and Biosciences, University of Guelph, Campus d'Alfred, Alfred, ON, K0B 1A0, Canada \\ ‡Department of Population Medicine, Ontario Veterinary College, University of Guelph, Guelph, ON, N1G 2W1, Canada
}

\section{ABSTRACT}

The objective of this study was to assess the effect of different feed types and method of feed presentation in the first 12 wk of life on the feeding behavior, intake, and growth of calves fed a high milk level. Forty-eight neonatal Holstein calves were individually housed and randomly assigned to 1 of 4 treatments and fed solid feed ad libitum: silage-based total mixed ration (TMR), concentrate $(\mathrm{CON})$, and chopped hay and concentrate presented in 2 manners: mixed (MIX) or separate (SEP). All calves were offered $12 \mathrm{~L} / \mathrm{d}$ of acidified milk replacer $(1.8 \mathrm{~kg}$ of dry matter) until d 38 at which time step-down weaning by $1 \mathrm{~L} / \mathrm{d}$ began. At d 50 calves no longer received milk, and all calves on SEP and CON treatments were offered the MIX diet until the end of the trial, whereas TMR and MIX calves did not change feeds. Feed intakes were recorded daily, and calves were weighed twice per week. Rumination time was observed on the last $3 \mathrm{~d}$ of alternate weeks (wk 3 , $5,7,9$, and 11) for $1 \mathrm{~h}$ beginning at $1500 \mathrm{~h}$. Time spent feeding was determined for the last $2 \mathrm{~d}$ of alternate weeks. In the preweaning stage (d 1-37) average daily gain was similar for all calves $(1.1 \mathrm{~kg} / \mathrm{d})$. The TMR calves had lower average daily gain than calves on the other 3 treatments during both the weaning (d 38-49; 0.2 vs. $0.7 \mathrm{~kg} / \mathrm{d}$ ) and postweaning (d 50-84; 0.5 vs. 1.2 $\mathrm{kg} / \mathrm{d})$ stages. This result is related to the lower dry matter intake of calves fed TMR in comparison with MIX, SEP, and CON calves in the weaning (0.2 vs. 0.5 $\mathrm{kg} / \mathrm{d})$ and postweaning (1.8 vs. $2.8 \mathrm{~kg} / \mathrm{d}$ ) stages. Given dry matter content of the feeds (TMR $=52 \%$, other diets $=89 \%$ ), the as-fed intake of the calves was similar across treatments in all 3 stages. Calves offered hay in addition to concentrate showed no difference in concentrate intake in the first $7 \mathrm{wk}$ of life. Interestingly, TMR calves spent more time feeding during the postweaning stage than MIX, SEP, and CON calves (308 vs. 194

Received June 22, 2015.

Accepted August 29, 2015.

${ }^{1}$ Corresponding author: tdevries@uoguelph.ca min/d) and exhibited a slower feeding rate postweaning (5.9 vs. $14.4 \mathrm{~g}$ of dry matter per minute). It appears that during weaning, and postweaning, calves fed TMR were attempting to maximize their nutrient intake but were unable to match that of calves in other treatments because of the high moisture content of their feed, and thus were unable to achieve similar average daily gain. Additionally, growth and total intake throughout the preweaning and weaning stages were similar for calves fed chopped hay along with concentrate and those not offered hay, suggesting no detrimental effect of feeding forage.

Key words: dairy calf, feeding behavior, forage, weaning

\section{INTRODUCTION}

Increasing the level of milk feeding for dairy calves in the early weeks of life can enhance growth rates (Appleby et al., 2001; Jasper and Weary, 2002) and may also result in development of healthier, higher-producing cows (Terré et al., 2009; Soberon et al., 2012). A potential challenge of enhanced milk feeding appears at weaning. Traditionally fed calves, consuming low quantities of milk, are encouraged to ingest higher levels of concentrate before weaning (Khan et al., 2007a). Alternatively, calves fed higher levels of milk experience a challenge at weaning because of low consumption of solid feed before weaning (Jasper and Weary, 2002); thus, some concern exists that their digestive systems are not accustomed to the digestion of such feed at weaning (Terré et al., 2007). Despite implementation of gradual weaning programs, a decrease in overall DMI is an issue for high-milk-fed calves (de Passillé et al., 2011).

The provision of forages, such as hay, may improve feed intake and rumen development (Castells et al., 2012). Previously, the inclusion of forage in the diets of milk-fed calves was discouraged, despite the fact that this ingredient aids in muscular development of the rumen (Hamada et al., 1976), because it was also thought to inhibit the development of the rumen papil- 
lae (Tamate et al., 1962). In several studies, hay intake has been reported to displace the intake of higher quality starter (Stobo et al., 1966; Kertz et al., 1979; Hill et al., 2008). However, much of the research that contributed to that idea was conducted on calves fed low levels of milk that were insufficient for optimal growth. Recently, Khan et al. (2011) showed evidence that providing hay to calves fed with high milk allowances resulted in increased solid feed intakes and normal rumen development. These authors indicated that in a situation of restricted nutrient availability, hay intake could displace starter intake because of the resultant gut fill from consuming large amounts of hay. However, in a high-milk-feeding system, a gradual weaning program is typically recommended, ensuring a gradual transition from liquid to solid feed (Sweeney et al., 2010). Additionally, an improvement in digestibility was reported by Montoro et al. (2013) when concentrate was mixed with coarsely chopped grass hay rather than the finely chopped alternative. This novel finding suggests that not only forage type, but forage particle size, may also play a role in rumen development of young calves.

Recently, interest exists in providing calves fed higher milk levels with a silage-based TMR. Not only would TMR be practical for the dairy farmer, as they could potentially use the same TMR given to the lactating cows, but it could also provide a balanced, palatable source of nutrients for the developing young ruminant. This type of high-fiber ration could potentially encourage rumen development and, therefore, create a smoother transition to solid feed. Thus, the objective of this research was to investigate a feeding strategy that could be used to ease the transition to solid feed using different types of higher forage diets. It was hypothesized that incorporating a silage-based TMR into the diets of calves fed high levels of milk before weaning would have no detrimental effects on calf growth and result in a positive effect on feeding behavior. Similarly, it was hypothesized that calves fed diets including forage would exhibit more rumination behavior. Calves provided with forage were hypothesized to consume more solid feed than calves fed only concentrate. As a result it was expected that calves fed forage and mixed diets would devote a greater portion of the daily time budget to feeding than calves fed no forage.

\section{MATERIALS AND METHODS}

\section{Animals and Housing}

Forty-eight male Holstein calves were used in this study in 2 blocks of 24 calves. Each block was run over a 12 -wk period. The first block ran from April to July and the second from July to October. Calves were purchased from local dairy farms in Eastern Ontario (Canada) before $1 \mathrm{~d}$ of age. National Livestock Identification for Dairy tags (Allflex Canada, St. Hyacinthe, Canada) were applied before removal from the farm of origin. It was confirmed that calves received at least one feeding of colostrum before pickup. At the time of purchase each calf was assessed by the study technicians, and only calves deemed healthy and alert were included in the study. Calves were transported $<25$ $\mathrm{km}$, in a well-bedded compartment, from their farm of origin to the University of Guelph Kemptville Campus Dairy Education and Research Centre (Kemptville, ON, Canada). The date of arrival at the research center was marked d 0 for each calf. Upon arrival calves were managed under standard operating procedures of the research center, in accordance with the guidelines set by the Canadian Council on Animal Care (CCAC, 2009) and as approved by the University of Guelph Animal Care Committee. Calves each received a $2-\mathrm{mL}$ injection (i.m.) of a supplement containing vitamin $\mathrm{E}$ and selenium (Dystosel; Pfizer Animal Health, Kirkland, Canada) and a 1-mL injection of tulathromycin (Draxxin; Pfizer Animal Health) on d 0 to protect from illness (Stanton et al., 2013). In addition, they were given $2 \mathrm{~mL}$ of Inforce 3 (Pfizer Animal Health) intranasally for the prevention of respiratory disease caused by bovine respiratory syncytial virus, infectious bovine rhinotracheitis, and parainfluenza virus 3 (Ellis et al., 2013).

The calf barn at the research facility was a 3-sided building allowing for natural ventilation while protecting the pens from direct exposure to the elements. Calves were housed individually in pens $(1.2 \times 1.8 \mathrm{~m}$; width $\times$ depth) with 3 solid sides (1.3 m high) and a metal gate at the front that allowed calves to reach through for feed. The gate had 2 openings under which a bucket mount was fastened to hold feed pails. Preweaning calves had access to two 8-L capacity pails containing their solid feed. After weaning these pails were replaced with two 20-L capacity pails, one contained solid feed and the other was filled with fresh water. During the preweaning phase $20-\mathrm{L}$ pails were fastened to the rear corner of the pen for access to water. Pens were bedded with straw for the first week of life for added warmth and then switched to wood shavings thereafter, as per standard protocol at the research farm. Bedding was completely replaced twice weekly and replenished as needed.

\section{Milk Feeding Procedure}

Calves were offered acidified milk replacer daily at $0900 \mathrm{~h}$ from wk 1 through wk 7 . The milk feeding apparatus consisted of an artificial teat (Peach Teats, 
calves to assess feed sorting. Each sample taken was frozen at $-20^{\circ} \mathrm{C}$ until time of analysis.

Samples of fresh feed and orts taken for sorting analyses were analyzed by evaluating particle size distributions using a 3-screen Penn State Particle Separator. This apparatus separates the feed sample into 4 fractions: $>19 \mathrm{~mm}$ (long), $<19$ but $>8 \mathrm{~mm}$ (medium), $<8$ but $>1.18 \mathrm{~mm}$ (short), $<1.18 \mathrm{~mm}$ (fine) (Kononoff et al., 2003). After separation with the Penn State Particle Separator system, each fraction was dried in an oven at $55^{\circ} \mathrm{C}$ for $48 \mathrm{~h}$. All other fresh feed samples taken were also oven dried at $55^{\circ} \mathrm{C}$ for $48 \mathrm{~h}$ before being ground to pass through a $1-\mathrm{mm}$ screen using a Wiley Mill (Arthur H. Thomas Co., Philadelphia, PA). Ground feed component samples were pooled together into 2 samples per replicate (wk 3-8 and wk 9-12), and ground fresh samples of each diet were pooled together into 3 samples per replicate (wk 3-5, wk 6-8, and wk 9-12). Pooled samples were sent to Cumberland Valley Analytical Services Inc. (Maugansville, MD) for analysis of DM $\left(135^{\circ} \mathrm{C}\right.$; AOAC International, 2000: method 930.15), ash $\left(535^{\circ} \mathrm{C}\right.$; AOAC International, 2000: method 942.05), ADF (AOAC International, 2000: method 973.18), NDF with heat-stable $\alpha$-amylase and sodium sulfate (Van Soest et al., 1991), and CP $(\mathrm{N} \times 6.25$; AOAC International, 2000: method 990.03; Leco FP528 Nitrogen Analyzer, Lecom St. Joseph, MI). Additionally, NFC content was calculated as $100-(\% \mathrm{CP}$ $+\% \mathrm{NDF}+\%$ fat $+\%$ ash $)(\mathrm{NRC}, 2001)$.

To asses rumen development in calves, blood BHB concentration was measured (Brown et al., 2014) using a Precision Xtra meter (Abbott Diabetes Care, Saint Laurent, Canada; validated in cows by Iwersen et al., 2009) and blood ketone test strips (Abbott Diabetes Care) on d 7 of wk $3,5,7,9$, and 11 . Tests were performed by drawing a very small amount of blood $(<1$ $\mathrm{mL}$ ) from the coccygeal vein using a 23-gauge needle and 1-mL syringe. A droplet of blood was placed on the test strip, and the reader indicated results of blood BHB concentration in millimoles per liter.

\section{Calf Behavior}

Calf behavior was recorded continuously for all calves in the second study replicate $(\mathrm{n}=24$ calves, 6 calves per treatment) using 8 color video cameras (day-night camera, model no. WV-CP504; Panasonic, Osaka, Japan). Each camera was equipped with an F0.95/2.8- to 8-mm lens (Fujinon CCTV lens; Fuji, Tokyo, Japan). Video feeds from all 8 cameras were available for recording and viewing on a digital video recorder (digital disk recorder, model no. WJ-HD616K; Panasonic). Video recordings were set at 15 images per second.
Each camera was mounted approximately $2 \mathrm{~m}$ in front of the pens and $4 \mathrm{~m}$ from the floor of the barn. Each of the 24 pens had a camera capable of viewing the entire front gate of the pen where feed buckets and milk apparatuses were mounted. To facilitate nighttime viewing, 5 red lights $(100 \mathrm{~W})$ were set on timers and spaced evenly between cameras to allow clear recording.

Calf behavior was observed for $24 \mathrm{~h} / \mathrm{d}$ on 2 consecutive days at the end of alternate weeks (d 6 and 7 of wk $3,5,7,9$, and 11) for all calves in the second block ( $\mathrm{n}=24$ calves). Because of technical issues with one of the cameras during wk 11, 2 calves did not have video recordings available for analysis. During the entirety of the study, video was analyzed using instantaneous scans at 1-min intervals for milk feeding and solid feed consumption (as validated by Miller-Cushon and DeVries, 2011a). Milk feeding was defined as a calf having its mouth closed on the teat and with milk flowing through the hose. Solid feed consumption was defined as the calf head lowered into the feed pail. Feedingtime data were averaged across the 2 observation days to obtain an average daily feeding time per calf for each of the recorded weeks. Calves fed the SEP diet before weaning had feeding-time values for both feeds separately, as well as total feeding time.

Rumination time was recorded by live observation on d 5, 6, and 7 of alternating weeks beginning on wk 3 . On these days 1-min scans were performed for $1 \mathrm{~h}$ beginning at $1500 \mathrm{~h}$ and ending at $1600 \mathrm{~h}$ for a total of 60 observations per calf per day. This observation period was chosen based on the effectiveness of a similar time frame in measuring calf behavior in a previous study by Eckert et al. (2015).

In addition to the collection of feeding behavior, calves were fitted with electronic data loggers (HOBO Pendant G Data Logger, Onset, Pocasset, MA) for $7 \mathrm{~d}$ on a biweekly schedule that began at the start of wk 3 to record standing and lying behavior (validated in calves by Bonk et al., 2013). Data were collected for daily standing and lying time as well as number of daily lying bouts. Loggers were secured to the rear leg using bandage tape (Vetrap Bandaging Tape, 3M, London, Canada) as per UBC AWP (2013).

\section{Calculations and Statistical Analysis}

Growth was measured as ADG during each week; ADG was calculated as the difference in BW for that week divided by $7 \mathrm{~d}$. Gain-to-feed ratio was calculated by dividing the total BW gain in a given week by the total DM consumed that week. Feeding rate was calculated by dividing total feeding time by grams of solidfeed DM consumed that day. 
To test for feed sorting, the DMI of each fraction of the Penn State Particle Separator was calculated and expressed as a percentage of the predicted DMI of that fraction based on a sample of the fresh feed (Leonardi and Armentano, 2003). The predicted intake of each fraction was calculated as the product of the DMI of the total diet multiplied by the DM percentage of that fraction in the fresh feed. Values equal to $100 \%$ indicated no sorting, $<100 \%$ indicated selective refusals (sorting against), and $>100 \%$ indicated preferential consumption (sorting for). Sorting values were averaged to create one value per fraction per calf per week.

All data collected were summarized and analyzed by stage [preweaning (wk 1-5), weaning (wk 6, 7), and postweaning (wk 8-12)] and by week within stage. Before any analysis was performed, all data were tested for normality using the UNIVARIATE procedure of SAS (SAS Institute Inc., 2013).

Data were analyzed using the MIXED procedure of SAS, treating week as a repeated measure. The model included the fixed effects of treatment, week, and treatment-by-week interaction and the random effects of block and calf within block. Compound symmetry was selected as the variance-covariance matrix structure on the basis of best fit according to Schwarz's Bayesian information criterion. For the feed-sorting data, to determine whether sorting occurred, sorting activity for each fraction was tested for a difference from $100 \%$ by using the above-mentioned mixed model. All values reported are least squares means. Treatment differences were compared using the least squares means procedure with the PDIFF option and the Tukey-Kramer adjustment. Significance was declared at $P \leq 0.05$, and tendencies were reported if $0.05<P \leq 0.10$.

\section{RESULTS}

Nutrient compositions of the treatment diets are presented in Table 1 . The TMR diet had a low DM content compared with the other diets (Table 1). Although DM was not consistent across treatments, the NFC, CP, and ME levels of both TMR and MIX were similar. The TMR diet had much higher levels of ADF and NDF than both MIX and CON diets. The ME of the MIX diet was lower than that of the concentrate. The ME of the TMR was greater than ME of hay, although it was lower than that of the MIX and concentrate.

When measuring feed intake on an as-fed basis, treatments did not differ $(P=0.40)$ in all 3 stages of the trial (Figure 1a). Although all calves showed an increase in DMI with age, in the preweaning phase, TMR calves showed a tendency for lower DM solid feed consumption than calves on the other 3 diets (Table 2;
Figure 1b). During both the weaning and postweaning stages, calves on the MIX, SEP, and CON diets consumed more solid feed, on a DM basis, than calves fed TMR (Table 2). Calves offered hay and concentrate separately consumed $0.01 \pm 0.002 \mathrm{~kg} / \mathrm{d}$ of hay during the preweaning period and $0.05 \pm 0.013 \mathrm{~kg} / \mathrm{d}$ during the weaning period. Concentrate intake did not differ for calves fed the CON and SEP diets in both the preweaning $(P=0.91)$ and weaning $(P=$ $0.99)$ stages. Before weaning treatment interacted with week for milk replacer DMI (Table 2), likely reflecting week-to-week variation in milk consumption. Over the weaning phase milk replacer intake decreased over time (Table 2). Solid feed intake and total DMI showed an interaction of treatment and week during the weaning phase (Table 2). During wk 6 treatments did not differ in DMI; however, during wk 7 TMR calves had lower DMI than calves on the other diets $(P=0.01)$. During the postweaning stage an interaction of treatment and week effect was present for DMI. In wk 8 and 9 TMR calves consumed less solid feed than calves on the MIX and SEP treatments, respectively $(P=0.05)$. Later in the postweaning period, during wk 11 and 12, calves on all other treatments consumed more solid feed DM than TMR fed calves $(P=0.03)$.

Average daily gain did not differ across treatments in the preweaning stage (Table 2). During this time ADG decreased for all treatments by calf age (Table 2 ). Calves fed the TMR diet showed lesser gains across the weaning period and the postweaning stage (Table 2). While calves were being weaned, ADG decreased over time for all treatment groups (Table 2). Gain-tofeed ratio did not differ by treatment in the preweaning and postweaning phase; however, gain-to-feed ratio decreased with calf age during both of these stages (Table 2). During weaning, calves on the TMR treatment tended to have a lower gain-to-feed ratio than calves on SEP and CON diets $(P=0.08)$. Calves fed the MIX diet had a better gain-to-feed ratio than TMR calves $(P=0.01)$.

During both the preweaning $(34.2 \pm 6.33 \mathrm{~min} / \mathrm{d} ; P$ $=0.98)$ and weaning $(4.4 \pm 0.69 \mathrm{~min} / \mathrm{d} ; P=0.89)$ stages, treatment did not differ in milk feeding time. Also, treatments did not differ in rate of intake for milk replacer during the preweaning $(47.4 \pm 9.54 \mathrm{~g} / \mathrm{min} ; P$ $=0.67)$ or weaning $(145.5 \pm 21.40 \mathrm{~g} / \mathrm{min} ; P=0.94)$ stages. Preweaning, feeding time of solid feed did not differ across treatments, although feeding time increased with calf age (Table 3). A trend existed for calves fed the TMR diet to eat solid feed slower compared with calves fed the CON diet. During the weaning phase, solid-feed feeding time was greater for calves fed the TMR and MIX diets (Table 3). During this phase, feeding rate was lower for the TMR calves. Postweaning, 
TMR calves showed the longest feeding time and the slowest feeding rate of all 4 treatment groups (Table 3 ). Throughout the study lying time did not differ across treatments. Preweaning, all calves showed a decrease in lying time with age; however, in the postweaning stage calves showed an increase in lying time between wk 9 and 11 (Table 3). Frequency of lying bouts increased for all calves with age preweaning. Calves fed the TMR diet did, however, have fewer lying bouts per day in the postweaning stage (Table 3). No differences between treatments in rumination time were evident in the preweaning and postweaning stages (Table 3). Rumination time was higher for MIX calves than CON calves during the weaning stage. Rumination time increased with calf age during the preweaning stage (Table 3 ).
Calves fed the TMR diet did not exhibit sorting behavior throughout the trial (Table 4). Calves fed the MIX diet, regardless of diet preweaning, sorted against fine particles in wk 9. In wk 11, all calves on the MIX diet no longer sorted against fine particles and began to sort for short particles (Table 4).

No difference $(P>0.05)$ in blood BHB concentration (Figure 2) was observed during the preweaning (0.02 $\pm 0.015 \mathrm{mmol} / \mathrm{L})$ and weaning stages $(0.15 \pm 0.050$ $\mathrm{mmol} / \mathrm{L})$, although blood BHB concentration increased linearly $(P=0.03)$ across this time period. A clear difference existed in postweaning blood BHB concentration (Figure 2); calves fed the TMR diet showed much higher blood BHB level than calves fed the other diet (0.47 vs. $0.30 \mathrm{mmol} / \mathrm{L} ; \mathrm{SE}=0.06 ; P=0.03$ ).
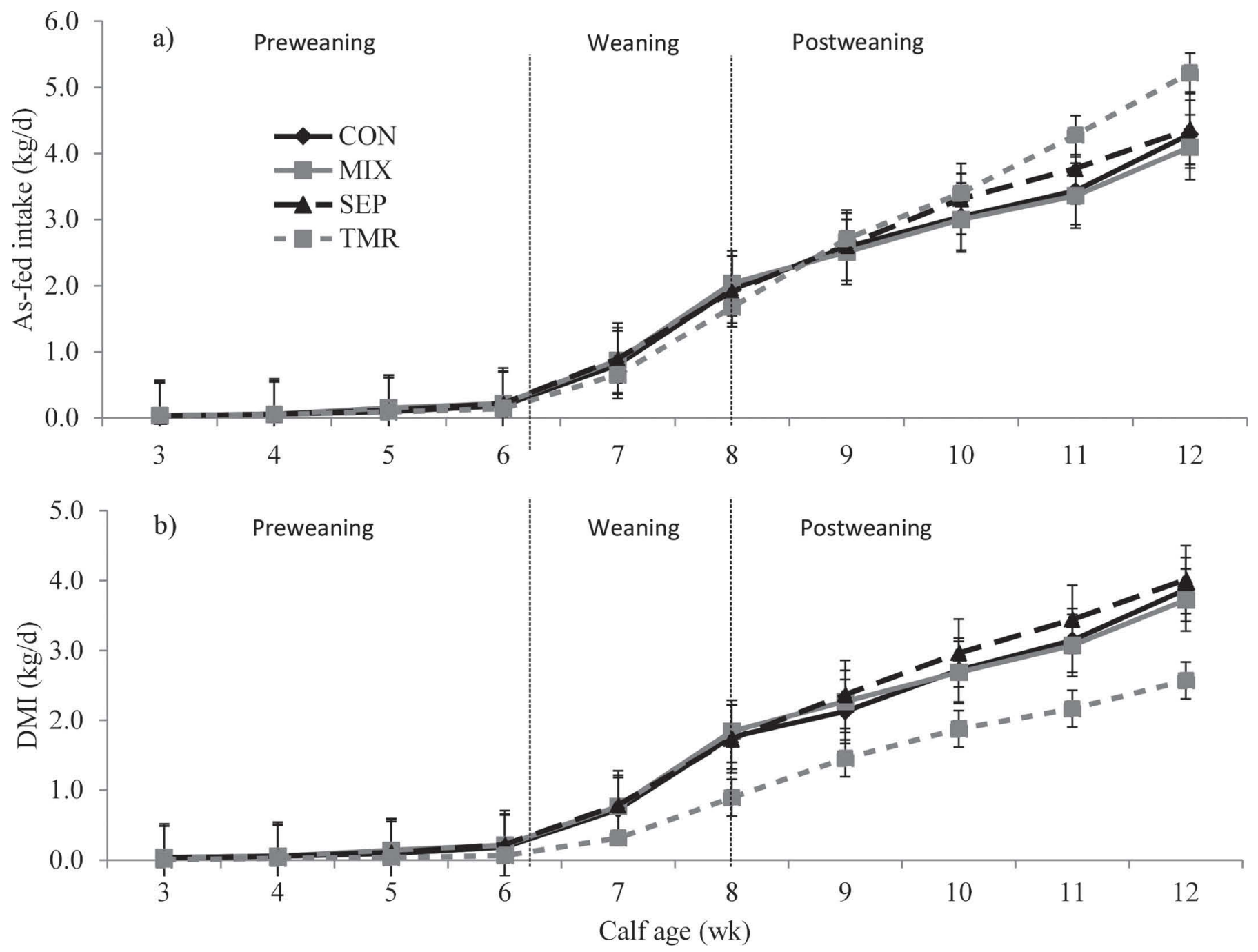

Figure 1. Mean $( \pm \mathrm{SE})$ weekly as-fed intake (a) and DMI (b). Values are shown separately for calves fed concentrate only preweaning (CON; $\mathrm{n}=12$ ), calves fed a mix of concentrate and chopped hay in a ratio of 85:15 (MIX; $\mathrm{n}=12$ ), calves fed chopped hay and concentrate in separate pails (SEP; $n=12)$, and calves fed a silage-based TMR (TMR; $n=12)$. All calves fed MIX, SEP, or CON were fed the MIX diet after weaning (wk 8 to 12 ). 
Table 2. Dry matter intake and BW gain of calves during preweaning, weaning, and postweaning stages ${ }^{1}$

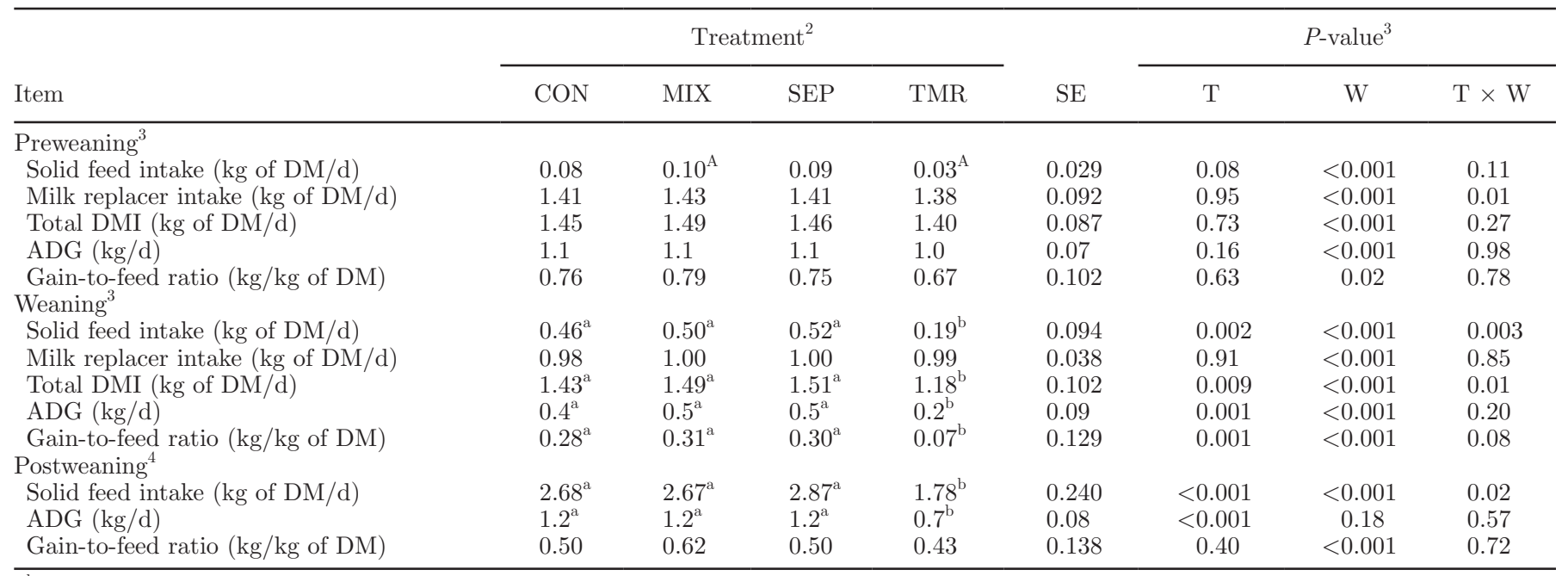

${ }^{\mathrm{a}, \mathrm{b}}$ Treatment means within a row with different superscripts differ $(P<0.05)$.

${ }^{\mathrm{A}}$ Treatment means within a row with same superscripts differ $(P<0.10)$.

${ }^{1}$ Data are averaged by week for each calf per treatment $(n=12$ per treatment).

${ }^{2} \mathrm{~T}=$ effect of treatment, $\mathrm{W}=$ effect of week, $\mathrm{T} \times \mathrm{W}=$ interaction between treatment and week.

${ }^{3} \mathrm{CON}=$ calves provided concentrate only, MIX $=$ calves provided mixture of $85 \%$ concentrate and $15 \%$ chopped hay, SEP $=$ calves provided concentrate and chopped hay in separate buckets, TMR = calves provided a silage-based TMR.

${ }^{4} \mathrm{CON}$, MIX, SEP calves were provided mixture of $85 \%$ concentrate and $15 \%$ chopped hay; TMR calves were provided a silage-based TMR

Table 3. Calf behavior during preweaning, weaning, and postweaning stages ${ }^{1}$

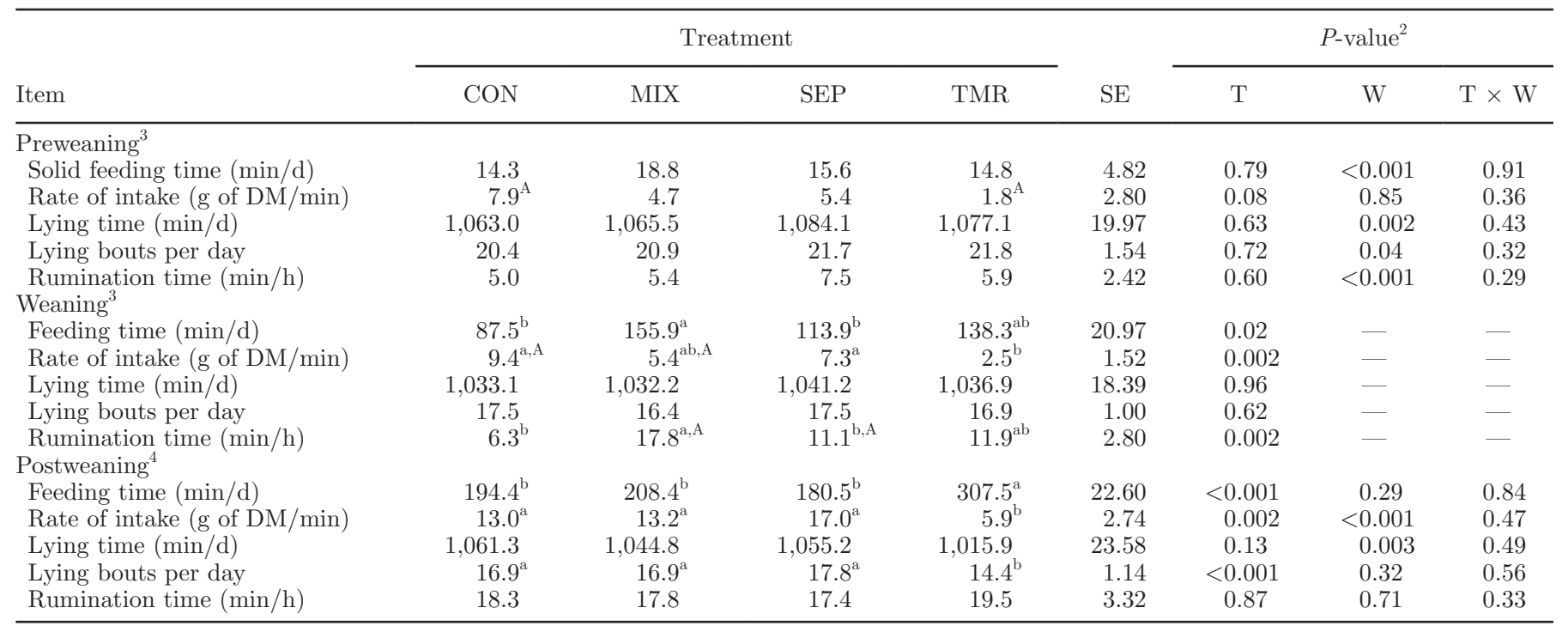

${ }^{\mathrm{a}, \mathrm{b}}$ Treatment means within a row with different superscripts differ $(P<0.05)$.

${ }^{\text {A }}$ Treatment means within a row with same superscripts differ $(P<0.10)$.

${ }^{1}$ Data are averaged by week for each calf per treatment $(n=6$ per treatment for measures of feeding time and rate of intake, $\mathrm{n}=12$ per treatment for all other measures; measured on alternate weeks only, i.e., wk 3, 5, 7, 9, and 11).

${ }^{2} \mathrm{~T}=$ effect of treatment; $\mathrm{W}=$ effect of week, $\mathrm{T} \times \mathrm{W}=$ interaction between treatment and week.

${ }^{3} \mathrm{CON}=$ calves provided concentrate only, MIX = calves provided mixture of $85 \%$ concentrate and $15 \%$ chopped hay, $\mathrm{SEP}=$ calves provided concentrate and chopped hay in separate buckets, TMR = calves provided a lactating-cow TMR.

${ }^{4} \mathrm{CON}$, MIX, SEP calves were provided mixture of $85 \%$ concentrate and $15 \%$ chopped hay; TMR calves were provided a lactating-cow TMR. 


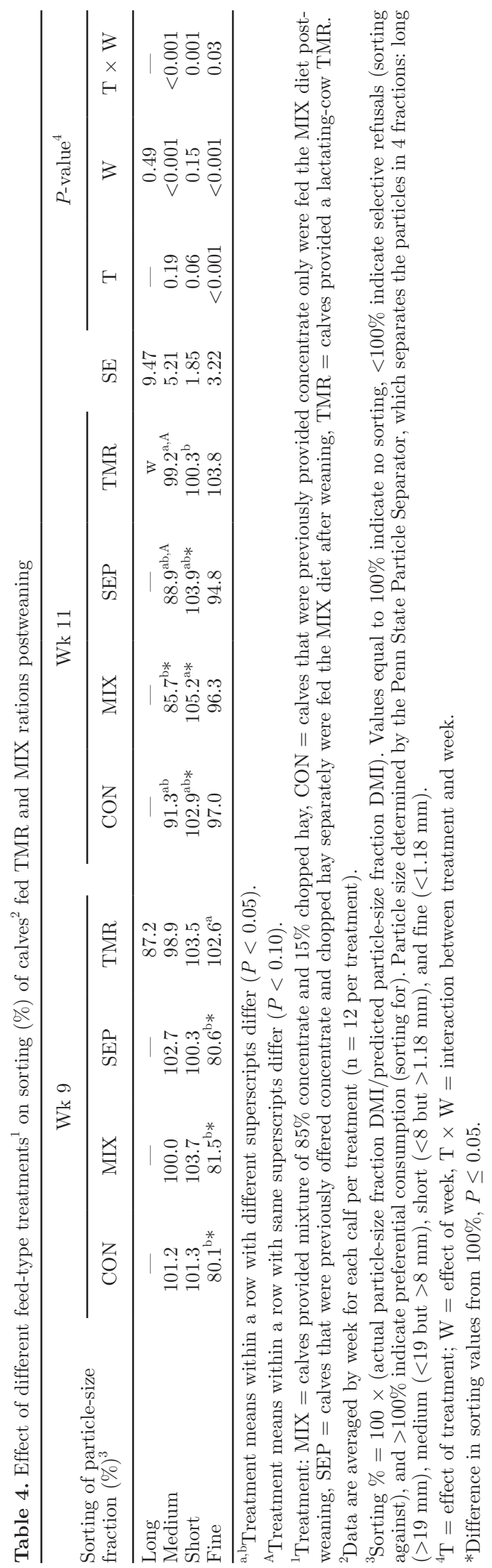

\section{DISCUSSION}

For calves to experience a smooth transition from liquid feed (milk) to solid feed at weaning, it is crucial to avoid loss of BW at this time. The goal of the present study was to determine the optimal solid feeding strategy for minimizing the negative effects of weaning. This target was achieved by all calves fed only concentrate or a mixture of hay and concentrate, but calves fed a silage-based TMR failed to attain this goal.

Despite increasing slightly with age, intake of solid feed remained very low until milk reduction began. The steady increase in DMI beginning at the start of the weaning program on the third day of wk 6 and ending on the first day of wk 8 is similar to findings of other studies that implemented a gradual weaning program (Khan et al., 2007a,b; Sweeney et al., 2010). Feed type and method of presentation did not affect DMI or ADG in the preweaning phase, which was consistent with the findings of other studies feeding high milk levels (e.g., Khan et al., 2011). Differences in DMI were not significant until the beginning of the weaning period, when milk intake was gradually decreased. Calves fed TMR still showed comparable intakes in wk 6 , but when milk continued to decrease during wk 7 , the difference in DMI between this treatment and calves fed MIX, SEP, and CON became greater. The difference in DMI persisted into the postweaning period when calves on the TMR treatment consumed approximately $1 \mathrm{~kg} / \mathrm{d}$ less DM than calves on the other treatments, contrary to our hypothesis. Although the TMR diet had a much lower DM content than the other diets, it also was high in NDF and ADF. Thus, before being able to meet nutritional needs from the TMR, calves on this diet likely felt full because of more rapid gut fill from the high moisture and fiber content of that feed (Drackley, 2008). It seems calves on the TMR diet were unable to achieve the same DMI as calves on all other treatments because of the high moisture content of their feed, despite attempting to maximize nutrient intake as shown by similar feed intake across treatments on an as-fed basis. Because of the large difference in moisture content, even if diets were balanced by nutrient composition, calves offered TMR would have needed to consume approximately $75 \%$ more feed on an as-fed basis to attain the same level of ME intake as calves fed the MIX diet during the postweaning period. This level of intake would likely not be biologically possible. It follows, therefore, that the TMR calves did not show growth rates and DMI comparable to their MIX-fed counterparts during weaning and afterward, primarily as a result of low DM and high fiber content of the feed offered. 


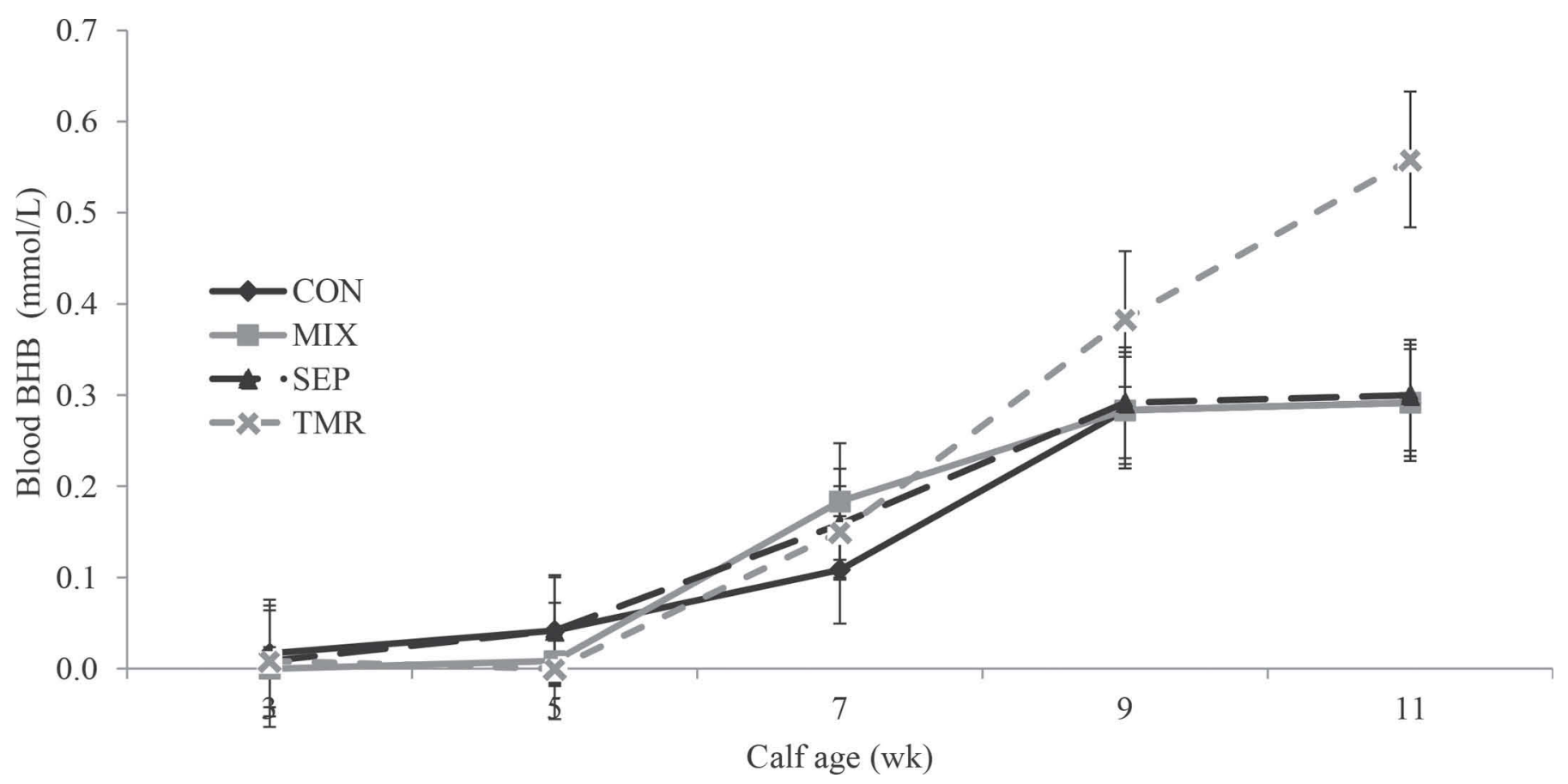

Figure 2. Mean $( \pm \mathrm{SE})$ blood BHB concentration of calves. Blood samples $(<1 \mathrm{~mL})$ were taken from the coccygeal vein. Values are results of testing using a Precision Xtra meter (Abbott Diabetes Care, Saint Laurent, Canada) in millimoles per liter. Samples were taken on d 7 of each alternate week. Values are shown separately for calves fed concentrate only preweaning $(\mathrm{CON} ; \mathrm{n}=12)$, calves fed a mix of concentrate and chopped hay in a ratio of 85:15 (MIX; $\mathrm{n}=12)$, calves fed chopped hay and concentrate in separate pails (SEP; $\mathrm{n}=12)$, and calves fed a silage-based TMR (TMR; $\mathrm{n}=12$ ). All calves fed MIX, SEP, or CON were fed the MIX diet after weaning (wk 8 to 12).

Although previous studies have shown a positive effect of hay intake on overall DMI (Khan et al., 2011; Castells et al., 2012; Castells et al., 2015), this experiment showed no detriment or benefit to the inclusion of forage in the form of chopped hay in the diet. Differing results could be attributed to the level of milk offered, the method of inclusion of the chopped hay, or the type of hay offered in the current study. Calves in the study by Castells et al. (2012) were offered less milk, and thus were consuming more solid feed before weaning than calves in the current study. Therefore, it is likely that differences in overall DMI were more pronounced in that previous study because of greater concentrate intake, results that may have been seen in the current study if the CON calves were fed only concentrate after weaning. Both Khan et al. (2011) and Castells et al. (2012) offered hay separately for the entire trial, whereas this study provided hay separately from concentrate in the preweaning and weaning stages and then in a mixture with concentrate after weaning. The level of hay consumed in our study is comparable to the range of forage intake found by Castells et al. (2012). Throughout the preweaning and weaning stages, although SEP and CON calves were offered concentrate on its own, there was no difference in concentrate intake or overall DMI. This reinforces the evidence that offering hay to calves fed high levels of milk causes no detrimental effects on intake of concentrate, which is crucial for rumen development (Stobo et al., 1966).

Because of the much lower DM consumption of the calves fed the TMR diet, the ADG achieved by this treatment group was much lower than the ADG of calves fed MIX, SEP, and CON diets from weaning time to the completion of the trial. A difference in ADG was likely not present in the preweaning phase as a result of a constant, high milk intake and low solid feed intake across all treatments, similar to findings of other studies feeding high levels of milk (e.g., Sweeney et al., 2010). The only difference in gain-to-feed ratio occurred during weaning when calves offered TMR showed lower gain to feed than all other calves. This difference is likely due to the change in primary nutrient source at this time; calves had to become more reliant on nutrients available from digestion of solid feed. The fermented forages included in the TMR may have been more difficult for calves to digest at this time (Drackley, 2008). However, it is likely that the lower DMI of calves fed TMR was a greater limiting factor in overall nutrient availability and growth in this study. It is interesting to note that calves on the TMR diet had a similar gain-to-feed ratio postweaning, suggesting that the digestibility of the type of feed itself was 
likely not the cause of the lesser ADG. It follows that even though these calves were able to digest the feed presented, they were unable to achieve sufficient DMI for similar growth.

Longer feeding times for MIX and TMR calves during the weaning period were expected because calves fed these diets involuntarily consumed higher levels of forage and thus had a more diluted nutrient source than the CON and SEP calves. Therefore, it follows that TMR and MIX calves would have a slower feeding rate at this transitional time. The TMR calves exhibited longer feeding times during both weaning and postweaning stages, which could be attributed to their low DM feed and high fiber content. Greter et al. (2008) found that adding greater levels of straw to the ration increased NDF and ADF while decreasing DMI and increasing daily feeding time in prepubescent heifers. Rumination time was not different between treatments during both the preweaning and postweaning stages. However, during the weaning phase, rumination time was higher for MIX calves than CON calves, once again coinciding with their high level of forage consumption during the same time period compared with calves fed the CON diet. Although total lying time did not differ between treatments, the number of lying bouts decreased for TMR calves during the weaning period; we speculate that this activity relates to the increased time spent eating by the TMR-fed calves.

In both wk 9 and 11, calves fed the TMR diet (at $52 \%$ DM) showed no sorting behavior. Although little previous research exists on feeding silage-based TMR to calves, sorting by adult dairy cows was lowered when fed a wet TMR (64\% DM) compared with a dry TMR (80\% DM; Leonardi et al., 2005). This may explain why calves fed the dry MIX diet $(\mathrm{DM}=89.8 \pm 0.8 \%)$, regardless of previous diet, exhibited some sorting behavior in the postweaning stage. These calves all sorted against fine particles in wk 9. Toward the end of the trial calves fed the MIX diet began to sort for short particles; a greater selection for short particles $3 \mathrm{wk}$ after weaning may indicate a desire to consume more concentrate, the higher energy portion of the feed to support high growth demands in this stage (Drackley, 2008; Miller-Cushon and DeVries, 2011b). Although $\mathrm{CON}$, SEP, and MIX calves were previously exposed to different feed treatments, no difference existed in sorting behavior of these calves postweaning, contrary to the findings of Miller-Cushon et al. (2013), who found that, when given the opportunity to sort the ration at this time, calves will continue to do so postweaning.

Treatment had no effect on blood BHB before weaning. All calves involved in the current study showed low BHB levels during the preweaning stage, when consuming little solid feed, and experienced a large increase over the weaning period as feed intake rose sharply. Blood BHB measurement has recently been used as an indicator of rumen development in dairy calves (Khan et al., 2011). Typically, grain-based calf starters are fed to increase solid feed fermentation for the production of higher levels of butyrate over the transition to solid feed to increase the development of ruminal papillae (Baldwin et al., 2004; Drackley, 2008). An increase in BHB has been shown to indicate a shift in source of nutrients from liquid feed to solids (Coverdale et al., 2004). Similar findings of BHB increase with age and feed intake have been recorded in previous studies of rumen development around the weaning time (Quigley et al., 1992; Coverdale et al., 2004). In the study by Quigley et al. (1992), a decrease in BHB and an increase in overall DMI were associated with the consumption of hay; however, in the current study all calves were fed hay after weaning, so the effects of feeding hay on BHB level are unclear. During the postweaning phase, the BHB level for TMR calves continued to increase, rather than plateauing as it did for MIX-fed calves. It is possible that the butyrate levels of the fermented feed contributed to the increased blood BHB levels in TMR calves. It would be speculative to comment in depth on the rumen development of these calves without further measures of rumen physiology. To date, no research has studied the effect of feeding silage on BHB level in calves; thus, this also requires further investigation.

\section{CONCLUSIONS}

These results suggest that preweaning solid feeding treatment has little effect on growth and intake of calves fed a high level of milk during this stage. However, difficulties arise during the weaning and postweaning phases when calves fed TMR are faced with the challenge of high moisture content in their main solid feed source. Therefore, these results suggest that diets with high DM levels, which may include a limited amount of chopped forage, are advantageous to the developing ruminant around weaning time, whereas those diets high in moisture and fiber are not recommended.

\section{ACKNOWLEDGMENTS}

The authors thank the staff and students at the University of Guelph, Kemptville Campus Dairy Education and Research Centre (Kemptville, ON, Canada). In particular, for their technical assistance, we thank Robin Crossley, Geisa Mainardes, Hannah Gillespie, Caylie Corvinelli, and Lisa Gordon. Morgan Overvest was supported by a Canadian Dairy Commission (CDC; Ottawa, ON, Canada) Graduate Scholarship. This project was funded through a Natural Sciences 
and Engineering Research Council of Canada (NSERC, Ottawa, ON, Canada) Discovery Grant (T. J. DeVries) and through funding from the Campbell Centre for the Study of Animal Welfare (CCSAW; University of Guelph, Guelph, ON, Canada).

\section{REFERENCES}

AOAC International. 2000. Official Methods of Analysis. 17th ed. Vol. 1. AOAC Int., Arlington, VA.

Appleby, M., D. M. Weary, and B. Chua. 2001. Performance and feeding behaviour of calves on ad libitum milk from artificial teats. Appl. Anim. Behav. Sci. 74:191-201.

Baldwin, R. L., VI, K. R. McLeod, J. L. Klotz, and R. N. Heitmann. 2004. Rumen development, intestinal growth and hepatic metabolism in the pre- and post-weaning ruminant. J. Dairy Sci. 87(ESuppl.):E55-E65.

Bonk, S., O. Burfeind, V. S. Suthar, and W. Heuwieser. 2013. Technical note: Evaluation of data loggers for measuring lying behavior in dairy calves. J. Dairy Sci. 96:3265-3271.

Brown, H. E., E. C. Eckert, M. A. Steele, T. J. DeVries, and K. E. Leslie. 2014. An evaluation of a calf-side betahydroxybutyrate test in dairy calves fed a high plane of nutrition and weaned at six versus eight weeks of age. J. Dairy Sci. 97(E-Suppl. 1):312.

Castells, L., A. Bach, G. Araujo, C. Montoro, and M. Terré. 2012. Effect of different forage sources on performance and feeding behavior of Holstein calves. J. Dairy Sci. 95:286-293.

Castells, L., A. Bach, and M. Terré. 2015. Short- and long-term effects of forage supplementation of calves during the preweaning period on performance, reproduction, and milk yield at first lactation. J. Dairy Sci. 98:4748-4753.

CCAC (Canadian Council on Animal Care). 2009. CCAC Guidelines on the Care and Use of Farm Animals in Research, Teaching and Testing. Canadian Counc. Anim. Care, Ottawa, ON, Canada.

Coverdale, J. A., H. D. Tyler, J. D. Quigley, and J. A. Brumm. 2004. Effect of various levels of forage and form of diet on rumen development and growth in calves. J. Dairy Sci. 87:2554-2562.

de Passillé, A. M., T. F. Borderas, and J. Rushen. 2011. Weaning age of calves fed a high milk allowance by automated feeders: Effects on feed, water, and energy intake, behavioural signs of hunger, and weight gains. J. Dairy Sci. 94:1401-1408.

Drackley, J. K. 2008. Calf nutrition from birth to breeding. Vet. Clin. North Am. Food Anim. Pract. 24:55-86.

Eckert, E., H. Brown, K. E. Leslie, T. J. DeVries, and M. A. Steele. 2015. Weaning age impacts growth, feed intake, gastrointestinal development and behavior of Holstein calves fed an elevated plane of nutrition during the pre-weaning stage. J. Dairy Sci. In press.

Ellis, J. A., S. P. Gow, S. Mahan, and R. Leyh. 2013. Duration of immunity to experimental infection with bovine respiratory syncytial virus following intranasal vaccination of young passively immune calves. J. Am. Vet. Med. Assoc. 243:1602-1608.

Greter, A. M., T. J. DeVries, and M. A. G. von Keyserlingk. 2008. Nutrient intake and feeding behavior of growing dairy heifers: Effects of dietary dilution. J. Dairy Sci. 91:2786-2795.

Hamada, T., S. Maeda, and K. Kameoka. 1976. Factors influencing growth of rumen, liver, and other organs in kids weaned from milk replacers to solid foods. J. Dairy Sci. 59:1110-1118.

Hill, T. M., H. G. Bateman, J. M. Aldrich, and R. L. Schlotterbeck. 2008. Effects of the amount of chopped hay or cottonseed hulls in a textured calf starter on young calf performance. J. Dairy Sci. 91:2684-2693.

Iwersen, M., U. Falkenberg, R. Voigtsberger, D. Forderung, and W. Heuwieser. 2009. Evaluation of an electronic cowside test to detect subclinical ketosis in dairy cows. J. Dairy Sci. 92:2618-2624.

Jasper, J., and D. M. Weary. 2002. Effects of ad libitum milk intake on dairy calves. J. Dairy Sci. 85:3054-3058.

Kertz, A. F., L. R. Prewitt, and J. P. Everett Jr. 1979. An early weaning calf program: Summarization and review. J. Dairy Sci. 62:1835-1843.
Khan, M. A., H. J. Lee, W. S. Lee, H. S. Kim, K. S. Ki, T. Y. Hur, G. H. Suh, S. J. Kang, and Y. J. Choi. 2007b. Structural growth, rumen development, and metabolic and immune responses of Holstein male calves fed milk through step-down and conventional methods. J. Dairy Sci. 90:3376-3387.

Khan, M. A., H. J. Lee, W. S. Lee, H. S. Kim, S. B. Kim, K. S. Ki, J. K. Ha, H. G. Lee, and Y. J. Choi. 2007a. Pre- and postweaning performance of Holstein female calves fed milk through step-down and conventional methods. J. Dairy Sci. 90:876-885.

Khan, M. A., D. M. Weary, and M. A. G. von Keyserlingk. 2011. Hay intake improves performance and rumen development of calves fed higher quantities of milk. J. Dairy Sci. 94:3547-3553.

Kononoff, P. J., A. J. Heinrichs, and D. R. Buckmaster. 2003. Modification of the Penn State forage and total mixed ration particle separator and the effects of moisture content on its measurements. J. Dairy Sci. 86:1858-1863.

Leonardi, C., and L. E. Armentano. 2003. Effect of quantity, quality, and length of alfalfa hay on selective consumption by dairy cows. J. Dairy Sci. 86:557-564.

Leonardi, C., F. Giannico, and L. E. Armentano. 2005. Effect of water addition on selective consumption (sorting) of dry diets by dairy cattle. J. Dairy Sci. 88:1043-1049.

Miller-Cushon, E. K., R. Bergeron, K. E. Leslie, G. J. Mason, and T. J. DeVries. 2013. Effect of early exposure to different feed presentations on feed sorting of dairy calves. J. Dairy Sci. 96:4624-4633.

Miller-Cushon, E. K., and T. J. DeVries. 2011a. Technical note: Validation of methodology for characterization of feeding behaviour in dairy calves. J. Dairy Sci. 94:6103-6110.

Miller-Cushon, E. K., and T. J. DeVries. 2011b. Effect of early feed type exposure on diet-selection behavior of dairy calves. J. Dairy Sci. 94:342-350.

Montoro, C., E. K. Miller-Cushon, T. J. DeVries, and A. Bach. 2013. Effect of physical form of forage on performance, feeding behavior, and digestibility of Holstein calves. J. Dairy Sci. 96:1117-1124.

NRC. 2001. Nutrient Requirements of Dairy Cattle. 7th rev. ed. Natl. Acad. Sci.,Washington, DC.

Quigley, J. D., T. M. Steen, and S. I. Boehms. 1992. Postprandial changes of selected blood and ruminal metabolites in ruminating calves fed diets with or without hay. J. Dairy Sci. 75:228-235.

SAS Institute Inc. 2013. SAS Version 9.4. SAS Inst. Inc., Cary, NC.

Soberon, F., E. Raffrenato, R. W. Everett, and M. E. Van Amburgh. 2012. Preweaning milk replacer intake and effects on long-term productivity of dairy calves. J. Dairy Sci. 95:783-793.

Stanton, A. L., D. F. Kelton, S. J. Leblanc, J. Wormuth, L. K. Fox, and K. E. Leslie. 2013. Effects of tulathromycin on incidence of various diseases and growth of young heifers. J. Am. Vet. Med. Assoc. 243:267-276.

Stobo, I. J. F., J. H. B. Roy, and H. J. Gaston. 1966. Rumen development in the calf. 2. The effects of diets containing different proportions of concentrates to hay on digestive efficiency. Br. J. Nutr. 20:189-215.

Sweeney, B. C., J. Rushen, D. M. Weary, and A. M. de Passillé. 2010. Duration of weaning, starter intake, and weight gain of dairy calves fed large amounts of milk. J. Dairy Sci. 93:148-152.

Tamate, H., A. D. McGilliard, N. L. Jacobson, and R. Getty. 1962. Effect of various dietaries on the anatomical development of the stomach in the calf. J. Dairy Sci. 45:408-420.

Terré, M., M. Devant, and A. Bach. 2007. Effect of level of milk replacer fed to Holstein calves on performance during the preweaning period and starter digestibility at weaning. Livest. Sci. 110:82-88.

Terré, M., C. Tejero, and A. Bach. 2009. Long-term effects on heifer performance of an enhanced-growth feeding programme applied during the preweaning period. J. Dairy Res. 76:331-339.

UBC AWP. 2013. UBC Animal Welfare Program: SOP - HOBO Data Loggers. pp. 1-23. Univ. British Columbia, Vancouver, Canada.

Van Soest, P. J., J. B. Robertson, and B. A. Lewis. 1991. Methods for dietary fiber, neutral detergent fiber on-starch polysaccharide in relation to animal nutrition. J. Dairy Sci. 74:3583-3597. 